\title{
La afiliación fraudulenta en el sistema de seguridad social integral colombiano ${ }^{1}$
}

\section{Fraudulent Affiliation in the Colombian Comprehensive Social Security System}

Guillermo Alfonso Maldonado Sierra ${ }^{2}$

Fecha de recepción: 30 de noviembre de 2016

Fecha de aprobación: 30 de marzo de 2017

\section{RESUMEN}

La afiliación fraudulenta a la seguridad social ha sido un asunto que de vieja data ha ocupado el interés de las autoridades nacionales, en razón del desequilibrio económico que puede generar al interior del Sistema y la defraudación de la confianza legítima de los ciudadanos que actualmente son inducidos a esta práctica por intermediarios que sacan provecho indebido del vacío legal existente. En la presente reflexión se hace un recuento de la evolución normativa y jurisprudencial de este fenómeno a la luz del Sistema General de Seguridad Social en Salud, el Sistema General de Pensiones y el Sistema General de Riesgos Laborales, para concluir que se carece de instrumentos jurídicos concretos para evitarlo y sancionarlo, aunado a que la jurisprudencia presenta un manejo ambiguo del tema, lo que impone varios retos de política pública al sistema.

1 Artículo producto del proyecto de investigación Características de la regulación e inspección, vigilancia y control de los intermediarios en la afiliación de los trabajadores independientes a la seguridad social en Colombia en los años 2005 a 2015, actualmente gestionado en la Universidad Santo Tomás. Bogotá, Colombia. DOI: http://dx.doi. org/10.15332/s1909-0528.2017.0002.03

2 Abogado de la Universidad Autónoma de Colombia. Bogotá, Colombia. Especialista en Derecho Constitucional de la Universidad del Rosario. Bogotá, Colombia. Candidato a Magister en Protección Social de la Universidad Santo Tomás. Bogotá, Colombia. Profesional Especializado de la Subdirección de Operación del Aseguramiento en Salud del Ministerio de Salud y Protección Social. Bogotá, Colombia. Correo electrónico: guillermomaldonado@usantotomas.edu.co 
Palabras clave: Afiliación fraudulenta, Corte Constitucional, Corte Suprema de Justicia, jurisprudencia, seguridad social, salud, pensiones, riesgos laborales.

\section{Abstract}

Fraudulent affiliation to social security has long been a matter of national interest, because of the economic imbalance that can generate within the System and defrauding of the legitimate expectations of the citizens who are currently induced to this practice by intermediaries who take advantage of the existing legal vacuum. In the present reflection, a summary of the normative and jurisprudential evolution of this phenomenon is made in light of the General System of Social Security in Health, the General Pension System and the General System of Occupational Risks, to conclude that legal instruments are lacking concrete to avoid and punish it, coupled with the fact that the jurisprudence presents an ambiguous handling of the subject, which imposes several public policy challenges to the system.

Keywords: Fraudulent affiliation, Constitutional Court, Supreme Court of Justice, Jurisprudence, Social security, Health, Pensions, Occupational risks. 


\section{INTRODUCCIÓN}

Según Avendaño (2014, p. 54), "la mayoría de las normas de Derechos Humanos tienen connotaciones positivas; por otra parte, el derecho laboral tiene algunas implicancias negativas; por lo tanto, su objeto suele confundirse con un deber". Desde la citada perspectiva, el artículo 83 de la Carta Política consagra la buena fe como un imperativo constitucional que debe regir las actuaciones de los particulares y las autoridades públicas, cuya garantía se concreta en forma de presunción en las gestiones que aquellos adelanten ante el Estado.

Sin embargo, este postulado no garantiza que las actuaciones jurídicas se encuentren exentas de fraude, lo que conlleva a que los ordenamientos generalmente incluyan sanciones de toda índole para desincentivar y disuadir esta práctica que, podría decirse, ha estado vigente de antaño en la humanidad, pues no en vano los romanos hicieron célebre el adagio "Fraus omnia corruptis" o "el fraude lo corrompe todo"; en Colombia, la seguridad social no ha sido ajena a esta problemática, toda vez que en su normatividad histórica también se han contemplado diversas medidas para evitarla y sancionarla.

El presente ensayo tiene como fin principal analizar este proceso en lo que concierne a la afiliación fraudulenta, precisando que aunque no existe un concepto estandarizado de la misma, se podría definir preliminarmente con fundamento en dicho análisis, como aquella que no guarda correspondencia con la situación real del trabajador y su grupo familiar, específicamente en su condición laboral, dependiente o independiente, o en la realidad económica de sus ingresos, con el fin de sacar provecho de las prestaciones asistenciales y económicas que otorga la seguridad social.

Este abordaje cobra particular relevancia en tanto que en el imaginario colectivo del país, siempre ha existido la creencia de que puede cotizarse al Sistema de Seguridad Social Integral (SSSI) en cualquier condición laboral o económica, sin importar si esta es o no concordante con la realidad, y que esta circunstancia no afecta la cobertura a los sistemas. 
Lamentablemente está práctica se viene presentando en la actualidad con mayor intensidad, por cuanto han proliferado intermediarios que sin contar con la autorización del Ministerio de Salud y Protección Social, conforme a los lineamientos del Libro 3, Parte 2, Título 6 del Decreto 780 de 2016, bajo distintas denominaciones inundan Internet y los postes de las principales ciudades del país con publicidad, ofreciendo a las personas la posibilidad de realizar los pagos a la seguridad social en porcentajes inferiores a los determinados por la normatividad vigente. (Diario del Otún, 2015; El Mundo, 2013; El Nuevo Siglo, 2015; El Tiempo, Finanzas Personales, 2015).

Posteriormente se apropian de manera ilegal de estos dineros y le generan a los trabajadores la confianza de estar cubiertos por la seguridad social cuando realmente no lo están, o proceden a su afiliación bajo una condición muy distinta a la real, bien sea simulando relaciones laborales inexistentes o sirviendo de medio para que las empresas "tercericen" en forma ilegal sus actividades misionales permanentes (Ministerio de la Protección Social, 2007; El Nuevo Día, 2013; Gaviria, 2013; Noticias RCN, 2015).

Así las cosas, desde el punto de vista metodológico, esta reflexión se enfocará en su primera parte a referenciar desde sus antecedentes más remotos, el tratamiento normativo que la afiliación fraudulenta a la seguridad social ha tenido en Colombia; en la segunda parte, se analizarán varias casuísticas en materia de salud, pensiones y riesgos laborales, contenidas en la jurisprudencia de la Sala Laboral de la Corte Suprema de Justicia y la Corte Constitucional, y en la tercera parte se presentarán las conclusiones del tema.

Finalmente es menester aseverar que si bien en la normatividad y la jurisprudencia examinada se le han atribuido varias acepciones al fenómeno de la afiliación fraudulenta a la seguridad social, entre ellas, la de irregular, falsa, indebida, ilegal, ineficaz, incorrecta, etc., para los fines de este ensayo se hará alusión a la afiliación fraudulenta como una categoría que enmarca a todas las anteriores. 


\section{ANÁlisis NORMATIVO DE LA AFILIACIÓN FRAUDULENTA A LA SEGURIDAD SOCIAL}

La afiliación fraudulenta a la seguridad social ha sido un asunto que de vieja data ha ocupado la atención de las autoridades nacionales, en gran parte por el desequilibrio económico que puede generar en el sistema. De esta forma, tenemos que desde el Decreto Ley 1650 de 1977, se facultaba en su artículo 29 al entonces Instituto de Seguros Sociales (ISS) para imponer multas a los patronos o trabajadores que incurrieran, entre otros, en el pago de cotizaciones por salarios inferiores a los efectivamente percibidos, el incumplimiento o la inexactitud en la remisión de los informes que fueran solicitados y la adulteración de documentos o certificados.

De igual manera, el Decreto 1138 de 1984, aprobatorio del Acuerdo 023 del mismo año, en virtud del cual el Consejo Nacional de Seguros Sociales Obligatorios expidió el "Reglamento del Seguro Social para los Trabajadores Independientes", en su artículo 14 otorgaba al ISS la potestad de desafiliar a los trabajadores independientes, entre otros, "Cuando se constate falsedad o inexactitud en la información solicitada en el artículo 4o del presente Reglamento”, norma que a su vez hacía alusión a los documentos que debían soportar la solicitud de afiliación de cada trabajador independiente.

Esta prerrogativa también fue reiterada en el Decreto 3063 de 1989, disposición que aprobó el Acuerdo 044 de 1989 del Consejo Nacional de Seguros Sociales Obligatorios, "por el cual se adopta el Reglamento General de Registro, Inscripción, Afiliación y Adscripción a los Seguros Sociales Obligatorios del Instituto de Seguros Sociales", en cuyo artículo 35 se permitía al ISS proceder a la desafiliación del trabajador "cuando se compruebe que se realizaron con fraude, error o cuando aparezca que no se tenía derecho a ellas o que este derecho se perdió" (sic), siendo de igual forma posible que exigiera al patrono o al trabajador el reembolso total de las prestaciones económicas y asistenciales cubiertas durante la afiliación o adscripción irregular, según lo establecía su artículo 38.

Ya en el ámbito de la Ley 100 de 1993 y el Sistema General de Seguridad Social en Salud (SGSSS), su artículo 183 prohibió a las EPS terminar en forma unilateral 
la relación contractual con sus afiliados, "salvo los casos excepcionales por abuso o mala fe del usuario, de acuerdo con la reglamentación que para el efecto expida el Gobierno Nacional".

Dicha reglamentación inició su desarrollo con la expedición del Decreto 1485 de 1994, norma en la que se estableció en el numeral 7 de su artículo 14 como una de las prácticas no autorizadas de las EPS, terminar en forma unilateral la relación contractual con sus afiliados, "salvo cuando exista prueba de que el usuario ha utilizado o intentado utilizar los beneficios que le ofrece el Sistema General de Seguridad Social en Salud en forma abusiva o de mala fe", catalogando como "conductas abusivas o de mala fe del usuario", las siguientes:

a) Solicitar u obtener para sí o para un tercero, por cualquier medio, servicios o medicamentos que no sean necesarios.

b) Solicitar u obtener la prestación de servicios del Sistema General de Seguridad Social en Salud a personas que legalmente no tengan derecho a ellos.

c) Suministrar a las entidades promotoras o prestadoras de servicios, en forma deliberada, información falsa o engañosa.

d) Utilizar mecanismos engańosos o fraudulentos para obtener beneficios del sistema o tarifas más bajas de las que le corresponderían y eludir o intentar eludir por cualquier medio la aplicación de pagos compartidos, cuotas moderadoras y deducibles.

Años después, el Plan Nacional de Desarrollo de los años 1999 a 2002, definido en la Ley 508 de 1998, en su capítulo de programas de inversión establecía en el numeral 4.3.1 de su artículo 4, que en aras de "garantizar la estabilidad financiera del Sistema General de Seguridad Social en Salud, SGSSS, y lograr el acceso a los servicios de salud con equidad", se evitaría "la múltiple afiliación al sistema y la afiliación fraudulenta”. 
Por la misma época, el artículo 64 del Decreto 806 de 1998 sancionaba con pérdida de antigüedad, es decir, con la carencia de los periodos mínimos de cotización necesarios para la prestación de algunos servicios de alto costo incluidos en el Plan de Obligatoriedad de Salud (POS) y definidos en su artículo 61, entre otras conductas, cuando 1) "un afiliado cotizante incluya a beneficiarios que deben ser reportados como cotizantes. En este evento perderán la antigüedad tanto el cotizante como los beneficiarios", 2) "un afiliado se reporte como empleador sin realmente serlo o cuando es reportado, a sabiendas, con salarios inferiores al real. Para este efecto bastará la prueba sumaria", 3) "un afiliado cotizante se afilie al Régimen Subsidiado sin tener el derecho correspondiente", y 4) "un trabajador independiente a través de actos simulados pretenda cotizar como trabajador dependiente, creando una vinculación laboral inexistente para todos los efectos legales”.

La norma en mención también atribuía esa sanción cuando el afiliado cotizante o beneficiario incurriera en conductas abusivas o de mala fe, trascribiendo literalmente las indicadas en el artículo 14 del Decreto 1485 de 1994 . Adicional a esta sanción, el artículo 14 del Decreto 047 de 2000 obligaba al afiliado cotizante a reembolsar a la EPS "el valor de los servicios obtenidos en virtud de dicha conducta", y en los casos de afiliación fraudulenta ordenaba a las EPS cancelar dicha afiliación "mediante comunicación fundamentada", facultando a estas personas a reingresar al SGSSS en la condición que realmente corresponde, previo cumplimiento de las normas de afiliación.

Asimismo, el artículo 82 del Decreto 806 de 1998 sancionaba la afiliación irregular con la pérdida del derecho al pago de incapacidades o licencias, a las personas que se afiliaran al sistema "argumentando relación laboral inexistente o con fundamento en ingresos no justificados", y si la conducta se determinaba con posterioridad al goce del derecho se debían efectuar los reembolsos de las prestaciones.

No obstante, el Decreto 1703 de 2002 en sus artículos 5 y 6 facultaba a las EPS para realizar auditorías a sus afiliados con el fin de verificar las "condiciones actuales de afiliación”, y en su artículo 11 fijó un procedimiento administrativo para la desafiliación, consistente en que la EPS debía remitir de manera previa una comunicación por correo certificado a la última dirección del afiliado, con una 
antelación no menor a un (1) mes, precisando las razones por las cuales procedía a la desafiliación "indicándole la fecha a partir de la cual se hará efectiva la medida", aclarando que en caso de controvertir la medida, la Superintendencia Nacional de Salud debía proceder conforme al artículo 77 del Decreto 806 de 1998.

Al poco tiempo, el Decreto 2400 de 2002 en su artículo 2, introdujo una reforma al artículo 10 del Decreto 1703 de 2002, en el sentido de añadir que también procedería la desafiliación de una EPS en los casos previstos en el numeral 7 del artículo 14 del Decreto 1485 de 1994, atinente a las conductas abusivas o de mala fe de los usuarios en el SGSSS, para lo cual las EPS debían presentar informes semestrales a la Superintendencia Nacional de Salud sobre los casos de desafiliación, y "enviar en forma previa al afiliado una comunicación en los términos establecidos en el artículo 11 del Decreto 1703 de 2002”.

Sin embargo, con la expedición de la Ley Estatutaria 1751 de 2015, en su artículo 10 se establecieron los derechos y deberes de las personas relacionados con la prestación del servicio de salud, siendo importante destacar como deberes los siguientes:

a) Usar adecuada y racionalmente las prestaciones ofrecidas, así como los recursos del sistema.

b) Cumplir las normas del sistema de salud.

c) Actuar de buena fe frente al sistema de salud.

d) Suministrar de manera oportuna y suficiente la información que se requiera para efectos del servicio.

El parágrafo 1 de la norma bajo estudio determinó claramente que "los efectos del incumplimiento de estos deberes solo podrán ser determinados por el legislador. En ningún caso su incumplimiento podrá ser invocado para impedir o restringir el acceso oportuno a servicios de salud requeridos", lo cual representa un giro trascendental en el abordaje de la afiliación fraudulenta al SGSSS, ya que supedita los efectos del incumplimiento de los deberes a la expedición de una ley que los regule, por lo que 
dejó sin fundamento jurídico el régimen sancionatorio anterior, cuya naturaleza era eminentemente derivada de la potestad reglamentaria del Gobierno Nacional.

Aunado a lo anterior, el parágrafo 2 de esta disposición ordena al Estado "definir las políticas necesarias para promover el cumplimiento de los deberes de las personas", lo cual es comprensible en la medida que la desafiliación si bien puede ser una medida eficiente en aras de salvaguardar la estabilidad financiera del SGSSS, para el afiliado y su grupo familiar puede representar la vulneración de sus derechos fundamentales a la vida, la salud y la seguridad social.

De ahí que en el artículo 89 del Decreto 2353 de 2015, que actualizó y unificó las reglas de afiliación al SGSSS, se hayan derogado todas las disposiciones reglamentarias relativas a las sanciones administrativas aplicadas por las EPS y motivadas por la afiliación fraudulenta, salvo las determinadas en el artículo 14 del Decreto 1485 de 1994.

Este cambio de enfoque filosófico introducido en la Ley Estatutaria 1751 de 2015 se empieza a evidenciar en el artículo 4 del Decreto 2353 de 2015, donde se parte de la base de la buena fe en las actuaciones de las personas ante el SGSSS y se presume que sus afirmaciones corresponden a la verdad material, esto "sin perjuicio de las denuncias que deban adelantar los actores ante las autoridades competentes cuando se tenga indicios de engaño o fraude al sistema o de que se están utilizando mecanismos engañosos o fraudulentos para obtener beneficios del sistema”.

El decreto en su artículo 8 prohíbe realizar afiliaciones individuales o colectivas a través de relaciones laborales inexistentes o por entidades que no estén debidamente autorizadas por el Ministerio de Salud y Protección Social, so pena de incurrir en un una práctica no autorizada que podrá ser investigada y sancionada por las autoridades competentes, y en su artículo 10 reitera como uno de los deberes de las personas en relación con el SGSSS, el "ejercicio de sus actuaciones de buena fe", y el "cumplimiento de las normas, reglamentos e instrucciones del sistema".

A su turno, el artículo 16 define la afiliación al SGSSS como "un acto que se realiza por una sola vez, por medio del cual se adquieren los derechos y obligaciones que 
del mismo se derivan", y en su parágrafo 2 solamente permite la desafiliación al sistema por el fallecimiento del afiliado, siendo este un viraje sustancial respecto de las normas anteriores que contemplaban la desafiliación del SGSSS, entre otros aspectos, por situaciones de fraude.

De otra parte y a diferencia del SGSSS, en materia pensional no se presentan desarrollos normativos tan amplios como los anteriormente esbozados que sancionen la afiliación fraudulenta al Sistema General de Pensiones (SGP), máxime cuando el artículo 13 del Decreto 692 de 1994 establece que por regla general la afiliación al SGP es permanente, independiente del régimen que seleccione el afiliado, pues esta no se pierde si se han dejado de cotizar uno o varios periodos, salvo que no se coticen seis o más, caso en el cual la afiliación se inactiva.

Inclusive el artículo 12 del decreto en mención es aún más garantista, en tanto que cuando la vinculación a una administradora no cumple con los requisitos mínimos establecidos, la entidad debe comunicarlo al solicitante y al respectivo empleador dentro del mes siguiente a la solicitud, y si superado ese lapso no se ha efectuado la comunicación, la norma dispone que "se entenderá que se ha producido dicha vinculación por haberse verificado el cumplimiento de todos los requisitos establecidos para el efecto"; de ahí que la jurisprudencia de la Sala de Casación Laboral de la Corte Suprema de Justicia sea más generosa en su casuística solo en los eventos de desafiliación por mora en los aportes patronales.

Sin embargo, la Ley 100 de 1993 en su artículo 53 introdujo a favor de las entidades Régimen Solidario de Prima Media con Prestación Definida (RPM) una potestad esencial para combatir las afiliaciones fraudulentas al sistema, en el sentido de facultarlas para fiscalizar e investigar a los empleadores o agentes retenedores de las cotizaciones, precisando que para ese fin podrían, 1) verificar la exactitud de las cotizaciones y aportes u otros informes, 2) adelantar las investigaciones que estimen convenientes, 3) citar o requerir a los empleadores o agentes retenedores de las cotizaciones para que rindan informes, 4) exigirles la presentación de documentos o registros de operaciones, y 5) ordenar la exhibición y examen de los libros, comprobantes y documentos para la correcta y oportuna determinación de las obligaciones. 
Por esta vía se ha decantado gran parte de la jurisprudencia que en sede de casación, ha proferido la Sala Laboral de la Corte Suprema de Justicia sobre afiliaciones fraudulentas al SGP, ya que esta facultad le permitía a las entidades administradoras del RPM contar con elementos para controvertir la situación real de un trabajador, tanto laboral como económica, todo lo cual se ratificó en la Circular 492 de 2002 del ISS.

En este aspecto tampoco se puede perder de vista que el artículo 91 de la Ley 488 de 1998 modificado por el artículo 99 de la Ley 633 de 2000, y la Ley 828 de 2003 en su artículo 8, facultan entre otras, a las EPS, las Administradoras de Fondos de Pensiones (AFP) y las ARP, para solicitar tanto a los afiliados cotizantes y beneficiarios, como a los empleadores, la documentación necesaria para constatar la veracidad de sus aportes o la acreditación de la calidad de beneficiarios.

Dicha prerrogativa se armonizó posteriormente con las nuevas facultades persuasivas, de sensibilización y fiscalización definidas para la Unidad de Gestión Pensional y Parafiscales (UGPP), en las Leyes 1151 de 2007 y 1607 de 2012, el Decreto Ley 169 de 2008 y el Decreto 575 de 2013, toda vez que el artículo 3 del Decreto 3033 de 2013 establece que si los aportantes no corrigen las inconsistencias detectadas por la entidades administradoras del sistema, deberán informarlo a la UGPP para que en el marco de sus competencias adelante las acciones a que hubiere lugar.

Por otro lado, en el Sistema General de Riesgos Laborales (SGRL), el artículo 29 del Decreto Ley 1295 de 1994, reiterado por el artículo 6 del Decreto 1772 de 1994, faculta a las Administradoras de Riesgos Laborales (ARL) para modificar la clasificación de la actividad económica reportada por los empleadores al momento de la afiliación y por ende la correspondiente cotización, siendo posible para ese fin que efectúen visitas a los lugares de trabajo en cualquier tiempo, sin perjuicio de dar aviso al Ministerio de Trabajo para lo de su competencia.

A pesar de que las normas específicas del SGRL no definen un régimen sancionatorio para situaciones de afiliación fraudulenta, en varias jurisprudencias de la Corte Suprema de Justicia y la Corte Constitucional, cuyo análisis se aborda en el acápite jurisprudencial, se observa que las ARL por analogía han venido dando aplicación 
a una figura del derecho de seguros para declarar la nulidad de las mismas, como es la reticencia, institución definida en el artículo 1058 del Código de Comercio colombiano, consistente en la obligación que tiene el tomador de un seguro de declarar "sinceramente los hechos o circunstancias que determinan el estado del riesgo, según el cuestionario que le sea propuesto por el asegurador", y la nulidad relativa que genera la inexactitud en la información sobre los hechos que hubieren retraído al asegurador de celebrar el contrato o a estipular cláusulas más onerosas.

De manera que el estado actual del marco normativo de la afiliación fraudulenta al SSSI, permite concluir de una parte que se ha avanzado al prohibir las desafiliaciones unilaterales por parte de las EPS, en garantía de los derechos fundamentales de sus afiliados a la vida, la salud, la seguridad social, el debido proceso y el principio de la buena fe.

No obstante, con la expedición de la Ley Estatutaria 1751 de 2015 se generó un vacío normativo, en el sentido que en la actualidad no se derivan sanciones específicas para las personas o entidades que incurren en afiliación fraudulenta al SGSSS; igual conclusión se puede predicar de la normatividad del SGP y el SGRL, lo que se constituye en caldo de cultivo para que intermediarios inescrupulosos sigan derivando provechos indebidos del sistema y afectando las coberturas que provee a las personas incautas que se afilian y pagan la seguridad social a través de aquellos.

Asimismo, si bien las entidades administradoras del SSSI cuentan con facultades para verificar la realidad laboral y económica de sus afiliados, esta labor debería realizarse en forma intensiva para prevenir esta problemática, a fin de que la UGPP y demás entidades que tengan algún grado de injerencia en el tema, tales como el Ministerio de Trabajo, el Ministerio de Salud y Protección Social, las superintendencias, entre otras, haciendo uso de su marco de competencias generales investiguen y sancionen a estos intermediarios. 


\section{ANÁlISIS JURISPRUDENCIAL DE LA AFILIACIÓN FRAUDULENTA AL SSSI}

\subsection{Sistema General de Seguridad Social en Salud (SGSSS)}

Son pocos los hallazgos jurisprudenciales relacionados con la afiliación fraudulenta al SGSSS, amén que los escasos precedentes del tema se encuentran en algunas sentencias de la Corte Constitucional, donde son más comunes los atinentes a la desafiliación por mora en los aportes.

Un primer referente se constató en la Sentencia T-730/99, donde se analiza la situación en la cual una mujer embarazada fue afiliada al SGSSS como empleada doméstica de su cuñado y el ISS abruptamente le suspendió los servicios de salud, aduciendo que no podía estar afiliada por cuanto la normatividad sobre el tema prohíbe a los familiares del empleador dentro del quinto grado de consanguinidad, primero civil y tercero de afinidad, afiliarse como trabajadores del servicio doméstico.

La Corte revocó los fallos de los jueces de instancia y concedió la tutela ordenando al ISS prestar el servicio de salud a la accionante, al considerar que la actuación de dicho instituto era contraria a los derechos a la vida, al trabajo, a la salud, a la maternidad y a la igualdad, seguridad social, debiendo cotizar al sistema sobre la base general de un salario mínimo legal.

De modo similar, en la Sentencia T-1130/00 la Corte examinó el caso de una persona con diagnóstico de insuficiencia renal crónica terminal secundaria a uropatía obstructiva, que no cumplía con el periodo mínimo de cotización para acceder al tratamiento médico de alto costo para su enfermedad, que le había sido negado por el ISS debido a su afiliación fraudulenta toda vez que se afilió con posterioridad a octubre de 1998, fecha en la que estaban cerradas las inscripciones de nuevos afiliados al Régimen Contributivo de salud.

Igualmente, la Corte revocó el fallo de instancia e inaplicó por inconstitucional el artículo 61 del Decreto 806 de 1998 referente a los periodos mínimos de cotización y ordenó al ISS prestarle los servicios médicos al accionante, estimando que se estaba 
ante una discusión contractual de convalidación de pagos que el ISS había consentido en el tiempo y que ante una situación de urgencia no era dable oponer periodos mínimos de cotización, lo cual era violatorio de los derechos a la salud y la vida.

Otra casuística interesante se observa en la Sentencia T-094/02, que trató el caso de una persona que se afilió al SGSSS a través de una entidad agrupadora de trabajadores independientes que intermediaba ante el sistema en su afiliación y pago de aportes. La EPS le programó una cirugía y posteriormente le informó que había sido desvinculada del sistema en razón a que había solicitado a la Superintendencia de Salud información acerca de las empresas que podían actuar como agrupadoras, encontrando que su agrupadora no tenía permiso para fungir como tal, sancionándola con la pérdida de antigüedad en el SGSSS de conformidad con lo dispuesto en el artículo 64 del Decreto 806 de 1998.

La Corte revocó el fallo de instancia y ordenó a la EPS programar la cirugía ordenada a la accionante, dejando sin efecto su desvinculación al SGSSS por violación al debido proceso y la confianza legítima, resaltando lo siguiente:

Llama la atención la actitud asumida por la EPS demandada, lo que denota a todas luces una desorganización administrativa que la accionante no se encuentra en el deber constitucional de soportar. Esas irregularidades que generaron la desafiliación de la actora al sistema de seguridad social, debieron haber sido verificadas al momento de la afiliación, que en concepto de la Corte, es la oportunidad en que se deben examinar con detenimiento los requisitos que exige la ley para la afiliación al sistema contributivo de salud, en aras de garantizar los derechos fundamentales de los usuarios, quienes no tienen por qué padecer los desórdenes o la negligencia de la entidades promotoras de salud, a punto de poner en peligro su propia vida.

En la Sentencia T-1233/04, la Corte examinó el caso de una menor de edad con síndrome de pubertad precoz con deterioro de talla, a quien su EPS le negó el tratamiento médico arguyendo que esta enfermedad no ponía en riesgo su vida y que al hacer el estudio sobre la incapacidad económica de la su madre encontró inconsistencias en su afiliación y pagos de los aportes, pues el padre de la menor 
aparecía como beneficiario suyo y al tiempo era quien suscribía como empleador los formularios de autoliquidación de aportes, y además era titular de un contrato de medicina prepagada, donde aparecían como beneficiarias la madre y su hija menor.

La Corte revocó los fallos de instancia y amparó el derecho fundamental a la salud de la menor, ordenando el suministro del medicamento requerido durante todo el tiempo que fuera necesario según prescripción médica, dado el efectivo interés superior de los derechos de la menor.

Por último, la Sentencia T-1301/05 analiza el caso de un menor de edad con síndrome de Down (SD) a quien su médico tratante ordenó remitir a una institución hospitalaria de IV nivel para una operación inmediata por considerarlo de suma gravedad, por lo que sus progenitores acudieron a la EPS obteniendo una negativa al considerar que su afiliación era fraudulenta.

La Corte revocó el fallo de instancia y tuteló los derechos del menor, ordenando al Secretario de Salud del Departamento del Meta expedir las autorizaciones requeridas por los médicos tratantes, toda vez que los servicios médicos no habían sido prescritos por los galenos de la EPS, máxime que el accionante no había aportado la información necesaria para poder establecer cuáles servicios le fueron negados por la EPS accionada.

En conclusión, el análisis de la afiliación fraudulenta al SGSSS en sede de revisión de tutela, refleja que en el ejercicio hermenéutico han adquirido mayor preponderancia los derechos fundamentales de los afiliados a la vida, la salud y la seguridad social, sobre la misma condición irregular de su afiliación al sistema.

\subsection{Sistema General de Pensiones (SGP)}

La Sala Laboral de la Corte Suprema de Justicia ha estudiado en sede de casación varios casos de afiliación fraudulenta en pensiones, en los cuales es recurrente observar como parte demandada al ISS y la controversia sobre las investigaciones administrativas que adelantaba en el marco de lo dispuesto en las facultades de fiscalización e investigación previstas en el artículo 53 de la Ley 100 de 1993, 
específicamente en la condición laboral y económica del cotizante. A continuación, se reseñan algunas de las más importantes.

En Sentencia 12923 del 14 de diciembre de 1999, el ISS negó al demandante el reconocimiento de una pensión de invalidez de origen común, manifestando que en la investigación administrativa detectó varias anomalías, entre ellas que "el patrono que aparece en las autoliquidaciones de aportes nunca ha sido empleador del accionante y el hecho de que los pagos se efectuaron sin presentar novedad de ingreso, esto es, sin diligenciar el formulario de afiliación".

Las sentencias de primera y segunda instancia absolvieron al ISS y la Corte no casó los fallos cuestionados, al considerar que el actor no reunía el número mínimo de semanas de cotización exigido en la normatividad para acceder a la pensión de invalidez, aunado a que la investigación administrativa no tuvo incidencia en la decisión.

De la misma forma, en Sentencia 21375 del 16 de octubre de 2003 se examinó el caso en el cual el ISS concedió al actor la pensión de vejez sin los reajustes salariales solicitados, toda vez que determinó que algunos de los aumentos salariales declarados no correspondían a la realidad; en primera y segunda instancia se condenó al mencionado instituto a reconocer y pagar el valor del reajuste de la mesada pensional; no obstante la Corte casó la sentencia de segunda instancia bajo el siguiente argumento principal:

Por lo tanto, admitir que las cotizaciones no están sujetas a medida, que ellas son lo que a título de ellas se aporte, distorsiona un sistema concebido para ofrecer prestaciones con el fin de suplir ingresos en la vejez, por otro que hace más remunerativa la disminución de la capacidad laboral que su pleno ejercicio; la libertad para elevar los montos de los aportes durante periodos breves que inciden en el monto final de las prestaciones, conduciría al desequilibrio en la financiación del sistema, en el que los déficit han de ser enjugados por fondos comunes, los formados con aportes de todos los demás afiliados o del presupuesto nacional. La libertad de cotizaciones la ley solo la prevé en el artículo 62 de la Ley 100 de 1993 para un régimen de ahorro individual. 
Un caso similar se ventiló en la Sentencia 24136 del 8 de febrero de 2005, en el cual el demandante solicitaba la reliquidación de la pensión de vejez que le había sido reconocida por el ISS, ya que al calcularla no se tuvieron en cuenta sus aportes como trabajador independiente, como quiera que el afiliado no explicó las razones por las que había aumentado notoriamente sus cotizaciones. En primera y segunda instancia se condenó al ISS reliquidar la pensión, pero la Corte casó el fallo del adquem destacando del mismo lo siguiente:

Lo que aquí se pretende, es mantener el equilibrio financiero del sistema, evitando que por periodos cortos de cotizaciones como lo consentía el régimen anterior, se obtengan pensiones que no guarden proporción con el nivel real de ingresos. De esta manera, las fluctuaciones significativas de las cotizaciones por sí no pueden ser materia de reparo, sino cuando de ellas el afiliado no dé las explicaciones consistentes que justifiquen las variaciones, lo cual le incumbe por ser ese su deber probatorio, bien con motivo de la investigación administrativa que para el efecto adelante el ISS antes del reconocimiento de la pensión o aún para revisarla después de otorgada, ora en la órbita judicial, como ocurre en este proceso, en que la materia de examen era la validez de las cotizaciones que presentaban variaciones importantes.

Esta línea jurisprudencial se mantuvo en las Sentencias 30582 del 17 de octubre de 2008, 32135 del 28 de abril de 2009, 32144 del 4 de marzo de 2008, 33294 del 24 de febrero de 2009, 33479 del 23 de febrero de 2010, 35031 del 3 de agosto de 2010 y 35405 del 3 de marzo de 2009, siendo ratificada recientemente en la Sentencia 40984 del 27 de enero de 2016, donde también se dirimió un caso en que el actor solicitó al ISS el reconocimiento y pago de la pensión de vejez, que le fue negada bajo el argumento de que no tenía las semanas cotizadas necesarias para acceder al derecho, en razón a que la investigación administrativa había demostrado que unas semanas no serían tenidas en cuenta por la existencia de una afiliación indebida, pretensiones de las que en sentencia del $a$-quo se absolvió al ISS, fallo que fue revocado en segunda instancia. Empero, la Corte casó el fallo aludido insistiendo en la argumentativa anteriormente expuesta, así: 
Ese criterio del Tribunal no ha sido de recibo por la jurisprudencia reiterada de esta Corte, puesto que con él olvida el juzgador que el sistema general de pensiones se caracteriza por ser contributivo, lo que quiere decir que su principal fuente de financiación está en las cotizaciones de quienes están obligados a sufragarlas, carga que desde luego no puede ser ajena a los postulados de la buena fe, y por ende ungidas de los principios del sistema general de pensiones. Por esa razón, no puede quedar a merced del afiliado al sistema general de pensiones, realizar las cotizaciones sin tener en cuenta la calidad con la que se afilia, pues las prestaciones económicas que ofrece ese sistema penden de la validez de su afiliación y de las cotizaciones, es decir, que tanto una como otra deben hacerse con sujeción al cuerpo normativo que las regula.

En ese orden de ideas, la Corte ha mantenido una línea jurisprudencial homogénea y consistente a lo largo del tiempo, en la solución de los casos de afiliación fraudulenta al Régimen Solidario de Prima Media con Prestación Definida del SGP, en tanto que ha considerado dilatadamente que tanto la afiliación como las cotizaciones de las personas al sistema deben guardar correspondencia con la realidad, lo cual se constituye en un presupuesto elemental para acceder a las prestaciones que garantiza el SGP.

Sin embargo, en el Régimen de Ahorro Individual con Solidaridad (RAIS) este tema no parece ser tan relevante, en la medida que no se evidencian casuísticas jurisprudenciales relacionadas, y sus afiliados cuentan con la posibilidad de cotizar periódica u ocasionalmente valores superiores a los límites de su cotización obligatoria para incrementar los saldos de sus cuentas individuales, en los términos del artículo 62 de la Ley 100 de 1993.

Tampoco deja de ser reprochable que las entidades administradoras del RPM hicieran uso de sus facultades de investigación y fiscalización solo al momento en que la persona reclama su derecho pensional, lo que representa un riesgo inminente de defraudar la confianza legítima de sus afiliados. 


\subsection{Sistema General de Riesgos Laborales (SGRL)}

En materia de afiliación fraudulenta al SGRL existen varias sentencias tanto de la Sala Laboral de la Corte Suprema de Justicia como de la Corte Constitucional.

En efecto, la Sala Laboral de la Corte Suprema de Justicia en Sentencia 25725 del 2 de febrero de 2006, solventó un conflicto en el cual la demandante solicitaba la pensión de sobrevivientes, habida cuenta que su cónyuge había fallecido a causa de una anemia aguda debido a la laceración de pulmones producida por herida de proyectil de arma de fuego, siendo trabajador de una cooperativa de vigilancia y seguridad privada. Su ARP objetó el siniestro en razón a que el occiso era socio de la cooperativa y no ostentaba la calidad de trabajador dependiente. En primera instancia se condenó a la entidad demandada a reconocer la pensión de sobrevivientes, decisión que fue confirmada en segunda instancia, y en sede de casación la Corte no casó el fallo al argumentar que:

En estas condiciones, la Administradora de Riesgos Profesionales que está instituida para proteger tanto a trabajadores subordinados, independientes y asociados, luego de recibir la afiliación de cualquiera de estos, no le es dable sostener que no le cabe obligación o responsabilidad alguna, pues ello no tiene sentido, precisamente porque cuando la cooperativa a la cual pertenecía el occiso, se decide por la protección de la seguridad social a través de la ARP demandada, quedó subrogada en los riesgos profesionales, cumpliendo así con las preceptivas de los artículos 9 y 15 del Decreto 468 de 1990, quedando la accionada obligada a cubrir las prestaciones por el riesgo ocasionado, en los términos del ordenamiento vigente para la época, en este caso concreto, la pensión de sobrevivientes por la muerte del afiliado consagrada en el artículo 49 del estatuto de riegos profesionales dispuesto en el Decreto 1295 de 1994.

A su turno, la misma Corporación, en Sentencia 29809 del 2 de octubre de 2007, también analizó un caso en el que la demandante solicitaba se le reconociera la pensión de sobrevivientes, por cuanto su esposo había fallecido en forma violenta encontrándose en su labor habitual de conductor de taxi, y su ARP negó la prestación económica aduciendo que este no era trabajador dependiente de la cooperativa de 
taxis que lo afilió, sino que tenía la condición de trabajador independiente. De la misma forma, tanto el a-quo como el ad-quem condenaron a la demandada a reconocer y pagar la pensión de sobrevivientes a la demandante, decisión que la Corte no casó precisando que:

Así las cosas, es evidente que la afiliación realizada por la cooperativa a la ARP Colpatria estuvo apoyada en las preceptivas legales atinentes al tema, y si la empresa afiliada cumplió con las obligaciones emanadas de esa afiliación (no desvirtuada legalmente, pues las partes no demostraron haberla dejado sin validez, ni esta se ha visto afectada por decisión judicial), como acertadamente lo coligió el Tribunal, es obvio que la aseguradora está obligada legalmente a asumir los riesgos que eventualmente pudieran ocurrir, que para el caso específico corresponde a la pensión de sobrevivientes, como consecuencia del fallecimiento del asegurado Peláez Peláez, supuesto fuera de debate como lo dedujo el fallador de segundo grado, al igual que el número de semanas cotizadas y la condición de beneficiarios de las demandantes.

Casos similares con idénticas consecuencias jurídicas fueron fallados por la Corte en las Sentencias 34884 del 16 de marzo de 2010, 35164 del 28 de abril de 2009, 36227 del 21 de julio 2010, 38956 del 25 de octubre de 2011 y 41879 del 31 de julio de 2013.

En lo que concierne a la jurisprudencia de la Corte Constitucional, se destaca la Sentencia T-935/07, en la que se analiza un caso donde el accionante al desempeñarse como taxista tuvo una caída que le produjo graves secuelas y su ARP le negó el reconocimiento de la pensión de invalidez porque no tenía vínculo laboral con la empresa con la que cotizaba, pues conducía un taxi de propiedad de otra persona. En primera y única instancia le fue negado el amparo y la Corte en sede de revisión revocó lo anterior ordenando a la ARP reconocer y pagar al actor la indemnización por incapacidad permanente parcial, destacando de esta decisión lo siguiente:

12. Lo dicho muestra, precisamente, que el accionante no tenía más remedio que afiliarse al sistema de riesgos profesionales por intermedio de la empresa que constituyó un grupo de personas que se desempeñaban como taxistas 
(folio 2 del cuaderno 1), pues como lo dijo la ARP demandada "en caso de haber conocido que era un trabajador independiente no hubiera procedido a permitir su afiliación" (folio 7 del cuaderno 1). De este modo, es claro que el demandante también actuó de buena fe cuando se afilió a la ARP como trabajador vinculado a la empresa Grupo de Amigos, la Cumbia del Café, pues si bien la ley permitía que los trabajadores independientes se afilien al sistema de riesgos profesionales, en la práctica, eso solo era posible mediante la afiliación de una empresa.

La Sentencia T-648/09 examinó el caso en el cual una persona se vinculó al SSSI a través de una asociación de trabajadores independientes, y posteriormente sufrió un accidente de trabajo, siendo este objetado por su ARP por considerar que al momento de su ocurrencia no había relación laboral con la asociación de trabajadores independientes. En primera y segunda instancia se absolvió a la entidad demandada; empero la Corte revocó los fallos de instancia al considerar que:

Carecen, pues, de asidero las argumentaciones esgrimidas por la aseguradora en las instancias administrativas y judiciales, enfocadas a desconocer la asunción de la pensión de invalidez y, de otra parte, resulta desproporcionada la pretensión de someter su examen ante la justicia ordinaria laboral cuando la abstención manifiesta e injustificada de la ARP, demostradas las circunstancias adversas del peticionario, constituye sin duda vulneración ostensible del derecho al mínimo vital, conexo con los derechos a la vida y a la dignidad humana.

También se resalta lo dicho en la Sentencia T-176/11, providencia en la que se esgrime el caso en el que el representante legal de una asociación de trabajadores independientes, interpuso acción de tutela en contra de la ARP a la cual estaban afiliados sus miembros, toda vez que dicha entidad tomó la decisión unilateral de suspenderles la cobertura, como consecuencia de un accidente de trabajo en el cual falleció uno de sus trabajadores.

En ese sentido, la ARP le informó que aun cuando el accidente del trabajador se había presentado en desarrollo de sus actividades laborales, el mismo se produjo cuando 
prestaba sus servicios a favor de un tercero y no en virtud del contrato de afiliación que la asociación suscribió con la ARP, por lo que dicho evento se encontraba por fuera de la cobertura del sistema, aunado a que la entidad estaba ejerciendo funciones de afiliación colectiva de trabajadores, sin cumplir con los requisitos legalmente establecidos y sin tener autorización para el efecto.

Análogamente el amparo fue denegado en primera y segunda instancia, lo cual fue revocado por la Corte en revisión ordenando a la ARP mantener activa la afiliación al Sistema General de Riesgos Profesionales de todos los trabajadores independientes de la entidad, hasta tanto no se produjera una decisión por parte del entonces Ministerio de la Protección Social. Lo anterior toda vez que consideró que las ARP no tenían competencia legal para imponer sanciones administrativas de forma unilateral a sus afiliados, en los siguientes términos:

5.18. En ese orden de ideas, los conflictos administrativos surgidos con ocasión del incumplimiento de las obligaciones impuestas a los sujetos del SGRP deben ser resueltos, en sede administrativa, directamente por el Ministerio de la Protección Social, en representación del Estado, siendo dicho órgano el llamado a adoptar las medidas e imponer las sanciones a que haya lugar, en los términos previstos en las normas citadas. Ni la Constitución ni la ley, le reconocen facultades a las administradoras de riesgos profesionales, o a los empleadores, para imponer sanciones o adoptar medidas unilaterales, que conduzcan a la afectación de los derechos e intereses reconocidos a los trabajadores por el propio sistema, y que vayan en contravía de los objetivos del mismo, cual es, precisamente, el de proteger a la población trabajadora de las contingencias y daños sufridos con ocasión de los accidentes o enfermedades derivados de la actividad laboral.

De este modo, resulta entonces que la jurisprudencia referente a la afiliación fraudulenta al SGRL, tanto de la Corte Suprema de Justicia como de la Corte Constitucional, ha sido más garantista con el trabajador y su grupo familiar al no restringirles el acceso a las prestaciones que otorga el sistema, sin importar la condición de su afiliación, siendo dable inferir que las ARL cuentan con un margen de maniobra muy restringido para controvertir este aspecto, en tanto que instituciones 
jurídicas como la reticencia, en virtud de la cual declaran la nulidad de las afiliaciones fraudulentas, no han sido de recibo por la jurisprudencia como se pudo evidenciar.

\section{Conclusiones}

La idea consistente en que "el fraude lo corrompe todo" no ha sido tan absoluta en el SSSI, en razón a que la normatividad relacionada con la afiliación fraudulenta al SGSSS, si bien se ha ido transformando con el paso del tiempo en garantía de los derechos fundamentales de sus afiliados, ha generado un vacío normativo que omite la sanción a esta práctica, mientras que el andamiaje legal y reglamentario del SGP y el SGRL no ha contado desde sus orígenes con instrumentos jurídicos específicos para evitarla y sancionarla, salvo las limitadas facultades previstas en el artículo 53 de la Ley 100 de 1993, el artículo 91 de la Ley 488 de 1998 modificado por el artículo 99 de la Ley 633 de 2000 y el artículo 8 de la Ley 828 de 2003.

En el ámbito jurisprudencial, el abordaje del tema ha sido ambiguo, en tanto que de una parte varias casuísticas atinentes al SGSSS y el SGRL le han otorgado efectos jurídicos plenos a estas afiliaciones, y, de otra parte, las sentencias relacionadas con el SGP presentan un desarrollo jurisprudencial unificado y coherente que no ha otorgado validez a las mismas, circunstancia que representa un alto riesgo para las personas que incurren en esa conducta.

Este panorama impone el reto de fortalecer el marco regulatorio de la afiliación fraudulenta al SSSI, concretamente en la precisa definición de los efectos de esta práctica al interior del sistema, sin perjuicio de la inspección, vigilancia y control que el Estado debe realizar a los intermediarios que sacan provecho indebido del vacío normativo existente.

En este aspecto, es importante que las entidades administradoras del SSSI lleven a cabo ejercicios de verificación permanente de las condiciones reales de afiliación al sistema de los trabajadores y la veracidad de sus ingresos, insumo con el cual la UGPP y demás entidades competentes en el tema, podrían trabajar en forma coordinada para investigar e imponer las sanciones respectivas a estos intermediarios, 
habida cuenta que de esta práctica se podrían desprender responsabilidades no solo de índole administrativo, sino penales, civiles e incluso fiscales.

Por último, es indispensable generar políticas públicas que promuevan una cultura del cumplimiento de los deberes de las personas en el marco del SSSI, en especial de la afiliación y pago correcto de los aportes, en aras de proteger la confianza legítima que las personas depositan en el sistema.

\section{REFERENCIAS}

Avendaño, G. (2014). "El Derecho Laboral como Derecho Humano”. En Revista Verba

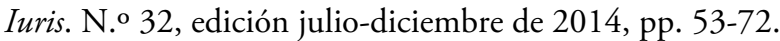

Diario del Otún. Económica (2015). Cuidado al afiliarse a riesgos laborales. Recuperado el 9 de junio de 2016, de http://www.eldiario.com.co/seccion/ECON\%C3\%93MICA/ cuidado-al-afiliarse-a-riesgos-laborales $1508 . \mathrm{html}$

El Nuevo Día (2013). Fraude en afiliaciones denunció Comfenalco. Recuperado el 9 de junio de 2016, a partir de http://www.elnuevodia.com.co/nuevodia/actualidad/ economica/180859-fraude-en-afiliaciones-denuncio-comfenalco

El Nuevo Siglo (2015). Alertan por falsas afiliaciones laborales. Recuperado el 1 de junio de 2016, a partir de http://www.elnuevosiglo.com.co/articulos/5-2015-alertan-por-falsasafiliaciones-laborales.html

El Tiempo. Finanzas Personales (2015). Alerta por afliación irregular a riesgos laborales. Recuperado el 1 de junio de 2016, a partir de http://www.eltiempo.com/economia/ finanzas-personales/alerta-por-afiliacion-irregular-a-riesgos-laborales/15804916

Gaviria Zapata, Luis Alexander (2013). Un análisis del fenómeno de la intermediación colectiva de la afiliación de los trabajadores independientes al Sistema General de Seguridad Social. Medellín: Universidad Santo Tomás. 
Ministerio de la Protección Social. Programa de Apoyo a la Reforma a la Salud, PARS (2007). Afiliación, pago y recaudo de aportes al Sistema General se Seguridad Social en Salud. Recuperado el 9 de junio de 2016, de https://www.minsalud.gov.co/Documentos\%20 y\%20Publicaciones/AFILIACION\%20PAGO\%20Y\%20RECAUDO.pdf

Noticias RCN (2015). Con publicidad en postes de Bogotá, estafadores ofrecen falsas afiliaciones a seguridad social. Recuperado el 9 de junio de 2016, de http://www.noticiasrcn. com/cazanoticias/publicidad-postes-bogota-estafadores-ofrecen-falsas-afiliaciones-seguridad-social. http://www.digore.com/

Periódico El Mundo. (2013). Cuidado con las estafas al afiliarse a la EPS - El Mundo. Recuperado el 1 de junio de 2016, a partir de http://www.elmundo.com/movil/noticia_detalle.php?idx=212001\&

República de Colombia. Corte Constitucional de Colombia (1999). Sentencia T-730/99. 1 de octubre de 1999. M.P.: Alejandro Martínez Caballero.

República de Colombia. Corte Constitucional de Colombia (2000). Sentencia T-1130/00. 28 de agosto de 2000. M.P.: Álvaro Tafur Galvis.

República de Colombia. Corte Constitucional de Colombia (2002). Sentencia T-094/02. 14 de febrero de 2002. M.P.: Alfredo Beltrán Sierra.

República de Colombia. Corte Constitucional de Colombia (2004). Sentencia T-1233/04. 9 de diciembre de 2004. M.P.: Clara Inés Vargas Hernández.

República de Colombia. Corte Constitucional de Colombia (2005). Sentencia T-1301/05. 9 de diciembre de 2005. M.P.: Jaime Córdoba Triviño.

República de Colombia. Corte Constitucional de Colombia (2007). Sentencia T-935/07. 8 de noviembre de 2007. M.P.: Marco Gerardo Monroy Cabra.

República de Colombia. Corte Constitucional de Colombia (2009). Sentencia T-648/09. 17 de septiembre de 2009. M.P.: Nilson Pinilla Pinilla. 
República de Colombia. Corte Constitucional de Colombia (2011). Sentencia T-176/11. 14 de marzo de 2011. M.P.: Gabriel Eduardo Mendoza Martelo.

República de Colombia. Corte Suprema de Justicia (1999). Radicación N.o 12923. Acta N. o 51. Del 14 de diciembre de 1999. M.P.: Germán G. Valdés Sánchez.

República de Colombia. Corte Suprema de Justicia (2003). Expediente N.o 21375. Acta N. ${ }^{\circ}$ 68. Del 16 de octubre de 2003. M.P.: Eduardo López Villegas.

República de Colombia. Corte Suprema de Justicia (2005). Expediente N.o 24136. Acta N.ำ 12. Del 8 de febrero de 2005. M.P.: Eduardo López Villegas.

República de Colombia. Corte Suprema de Justicia (2006). Radicación N. 25725. Acta N. ${ }^{\circ}$ 08. Del 2 de febrero de 2006. M.P.: Luis Javier Osorio López.

República de Colombia. Corte Suprema de Justicia (2007). Radicación N.o 29809. Acta N. 81. Del 2 de octubre de 2007. M.P.: Isaura Vargas Díaz.

República de Colombia. Corte Suprema de Justicia (2008). Radicación N.o 30582. Acta N. ${ }^{\circ}$ 51. Del 17 de octubre de 2008. M.P.: Gustavo José Gnecco Mendoza.

República de Colombia. Corte Suprema de Justicia (2009). Radicación N.o 32135. Acta N. ${ }^{\circ}$ 16. Del 28 de abril de 2009. M.P.: Gustavo José Gnecco Mendoza.

República de Colombia. Corte Suprema de Justicia (2008). Expediente N.o 32144. Acta N. ${ }^{\circ}$ 10. Del 4 de marzo de 2008. M.P.: Eduardo López Villegas.

República de Colombia. Corte Suprema de Justicia (2009). Radicación N.o 33294. Acta N. ${ }^{\circ}$ 07. Del 24 de febrero de 2009. M.P.: Gustavo José Gnecco Mendoza.

República de Colombia. Corte Suprema de Justicia (2010). Radicación N.o 33479. Acta N. ${ }^{\circ}$ 05. Del 23 de febrero de 2010. M.P.: Francisco Javier Ricaurte Gómez. 
República de Colombia. Corte Suprema de Justicia (2010). Radicación N.o 34884. Acta N. ${ }^{\circ}$ 08. Del 16 de marzo de 2010. M.P.: Francisco Javier Ricaurte Gómez.

República de Colombia. Corte Suprema de Justicia (2010). Radicación N.o 35031 Acta N. ${ }^{\circ}$ 27. Del 3 de agosto de 2010. M.P.: Elsy del Pilar Cuello Calderón.

República de Colombia. Corte Suprema de Justicia. (2009). Radicación N.o 35164. Acta N. 16. Del 28 de abril de 2009. M.P: Luis Javier Osorio López.

República de Colombia. Corte Suprema de Justicia (2009). Expediente N.o 35405. Acta N. 08. Del 03 de marzo de 2009. M.P.: Eduardo López Villegas.

República de Colombia. Corte Suprema de Justicia (2010). Radicación N.o 36227. Acta N. ${ }^{\circ}$ 25. Del 21 de julio de 2010. M.P: Camilo Tarquino Gallego.

República de Colombia. Corte Suprema de Justicia (2011). Radicación N.o 38956. Acta N. 36. Del 25 de octubre de 2011. M.P.: Carlos Ernesto Molina Monsalve.

República de Colombia. Corte Suprema de Justicia (2016). Radicación N. 40984 . Acta 002. Del 27 de enero de 2016. M.P.: Luis Gabriel Miranda Buelvas.

República de Colombia. Corte Suprema de Justicia (2013). Radicación N. ${ }^{\circ} 41879$. Acta N.o 23. Del 31 de julio de 2013. M.P.: Rigoberto Echeverri Bueno. 